\title{
Green Synthesis, Characterization and Magnetic Properties of Hausmannite Nanoparticles
}

\author{
N.M. DERAZ \\ Physical Chemistry Department, Laboratory of Surface Chemistry and Catalysis, \\ National Research Centre, Dokki, Cairo, Egypt \\ (Received November 18, 2018; revised version March 8, 2019; in final form March 22, 2019)

\begin{abstract}
Manganese oxides have an extreme importance in many industrial and environmental fields; so the scientists have sought to prepare these oxides in simple, cheap and environmentally friendly ways. From the viewpoint of economy efficiency and environmental demand, this article is aiming to prepare the most important oxide of manganese (hausmannite) in nanoscale by using combustion method via egg white. Scanning electron micrographs, energy dispersive X-ray and X-ray diffraction measurements display the structural and morphological properties of Mn oxide nanoparticles. The as-prepared systems are spongy, homogeneous and fragile. However, the vibrating sample magnetometry study shows that the as-prepared manganese oxides are found to be paramagnetic at room temperature.
\end{abstract}

DOI: 10.12693/APhysPolA.136.147

PACS/topics: hausmannite, XRD, SEM, EDX and magnetic properties

\section{Introduction}

Manganese oxides are important materials in various applications such as air pollution control, corrosioninhibiting pigment, high-density magnetic storage media, catalysts, ion exchange, molecular adsorption, electrochemical materials, batteries, varistors, solar energy transformation, electronics, and information technology [1-4]. Based on the extreme importance of manganese oxides in many industrial and environmental fields, scientists have sought to prepare these oxides in simple, cheap and environmentally friendly ways. In fact, there are many different ways to prepare manganese oxides through physical and chemical methods $[5,6]$. Unfortunately, these methods have many drawbacks that cannot be prevented or avoided which are represented in the presence of toxic organic solvents, production of hazardous by-products, and intermediary compounds and high energy consumption [7]. One revolutionary field of the modern era is nanotechnology whose main aim is to reach the best products with the least effort and at lowest costs while preserving the environment. Hence the full integration between nanotechnology and the green chemistry approach is very important due to the previous reasons. Green synthesis routes for materials are interesting due to various advantages of this synthesis such as low energy consumption, shot time for synthesis, reaction in nonequilibrium phase, high quality, simple facility, and high productivity. Thus, green preparation methods are good synthesis methods at low temperature due to redox reaction of nitrate salts (as oxidants) and organic compounds like egg white (as reductant, fuel), by which nanopowder can be synthesized easily.

corresponding author; e-mail: nmderaz@yahoo.com
Hausmannite is a complex oxide of manganese containing both di- and trivalent manganese. The formula can be represented as $\mathrm{Mn}^{2+} \mathrm{Mn}_{2}^{3+} \mathrm{O}_{4}$. It belongs to the spinel group and forms tetragonal crystals. The wide range of technological applications of $\mathrm{Mn}_{3} \mathrm{O}_{4}$ depends on its advantages as reported in [8-17]: (i) it is one of the most stable oxides of manganese. (ii) It is active catalyst for various catalytic reactions such as the decomposition of $\mathrm{NO}_{x}$, drinking water treatment process and the oxidation of both $\mathrm{C}_{6} \mathrm{H}_{6}$ and $\mathrm{CO}_{2}$. (iii) It can be used as an anode for lithium ion batteries. (iv) It is one of the most promising electrode materials for commercial super-capacitors. (v) The separate application of hausmannite nanoparticle is reported for dye remediation by adsorption or photocatalytic degradation. Hausmannite nanoparticles have been synthesized by various methods [12-23]. Overall, the synthesis mechanism of $\mathrm{Mn}_{3} \mathrm{O}_{4}$ can be divided into two main categories. The first category is the oxidative pyrolysis of manganese salts, such as the calcination method. The second category is the method for the oxidation of intermediate manganese hydroxide, $\mathrm{Mn}(\mathrm{OH})_{2}$, such as the solvothermal method.

The Deraz research group reported to formation and characterization of various spinels based on manganese via different preparation routes [24-26]. This group found that the combustion technique is capable of producing nanocrystalline materials, at a lower calcination temperature in a surprisingly short time. This quick, straightforward process can be used to synthesize homogeneous, high-purity, crystalline oxide ceramic powders including ultrafine hausmannite and its derivatives with a broad range of particle sizes.

This study is focused the formation and characterization of hausmannite nanoparticles by using combustion method depending upon egg white as new method for green synthesis of $\mathrm{Mn}_{3} \mathrm{O}_{4}$ NPs. 


\section{Experimental}

\subsection{Rapid synthesis of hausmannite nanoparticles}

One sample containing $\mathrm{Mn}$ oxide nanoparticles $\left(\mathrm{Mn}_{3} \mathrm{O}_{4} \mathrm{NPs}\right)$ was prepared by mixing calculated amount egg white $(2.5 \mathrm{ml})$ and manganese nitrate tetra hydrate $(2.51 \mathrm{~g})$ with vigorous stirring without $\mathrm{pH}$ adjustment. Then, the mixture was vigorously stirred at about $80^{\circ} \mathrm{C}$ until a dried precursor was obtained. The mixed precursors were concentrated in a porcelain crucible on a hot plate at $400{ }^{\circ} \mathrm{C}$ for quarter hour. The crystal water was gradually vaporized during heating and when a crucible temperature was reached, a great deal of foams produced and spark appeared at one corner which spread through the mass, yielding a voluminous and fluffy product in the container. Manganese nitrate employed in the present work was of analytical grade supplied by Prolabo Company. A general flowchart of the synthesis process is shown in Fig. 1.

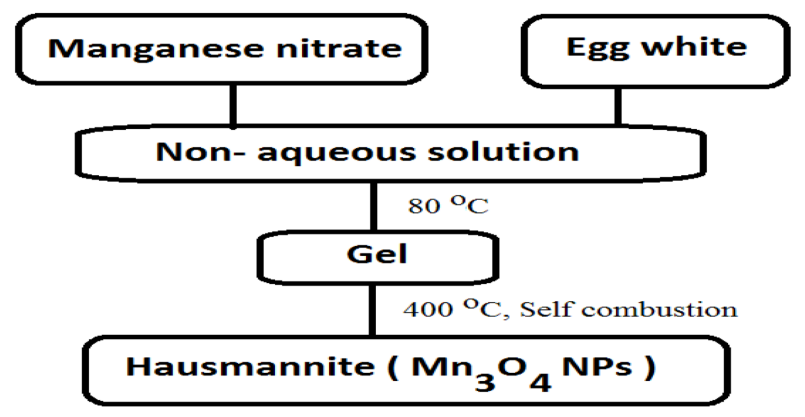

Fig. 1. Process flowchart for fabricating $\mathrm{Mn}_{3} \mathrm{O}_{4}$ NPs.

\subsection{Characterization technique}

An X-ray measurement of various mixed solids was carried out using a BRUKER D8 advance diffractometer (Germany). The patterns were run with $\mathrm{Cu} K_{\alpha}$ radiation at $40 \mathrm{kV}$ and $40 \mathrm{~mA}$ with scanning speed in $2 \theta$ of $2^{\circ} \mathrm{min}^{-1}$.

The crystallite size of $\mathrm{Mn}_{3} \mathrm{O}_{4}$ NPs present in the investigated solid was calculated by using the Scherrer equation based on X-ray diffraction line broadening [27]:

$$
d=\frac{B \lambda}{\beta \cos \theta},
$$

where $d$ is the average crystallite size of the phase under investigation, $B$ is the Scherrer constant (0.89), $\lambda$ is the wave length of X-ray beam used, $\beta$ is the full-width half maximum (FWHM) of diffraction, and $\theta$ is the Bragg angle.

Scanning electron micrographs (SEM) was recorded on JEOL JAX-840A electron microanalyzer. The sample was dispersed in ethanol and then treated ultrasonically in order to disperse individual particles over gold grids.

Energy dispersive X-ray analysis (EDX) was carried out on Hitachi S-800 electron microscope with an attached kevex Delta system. The parameters were as follows: accelerating voltage $15 \mathrm{kV}$, accumulation time $100 \mathrm{~s}$, window width $8 \mu \mathrm{m}$. The surface molar composition was determined by the Asa method, Zaf-correction, Gaussian approximation.

The magnetic properties of the investigated solid were measured at room temperature using a vibrating sample magnetometer (VSM; 9600-1 LDJ, USA) in a maximum applied field of $15 \mathrm{kOe}$. From the obtained hysteresis loops, the saturation magnetization $\left(M_{s}\right)$, remanence magnetization $\left(M_{r}\right)$, and coercivity $\left(H_{c}\right)$ were determined.

\section{Results and discussion}

\subsection{Structural characteristics}

Figure 2 shows the pattern of XRD for the as-prepared sample. The planes corresponding to $\left(\begin{array}{lll}1 & 0 & 1\end{array}\right),\left(\begin{array}{lll}1 & 1 & 2\end{array}\right),\left(\begin{array}{l}1 \\ 1\end{array}\right.$

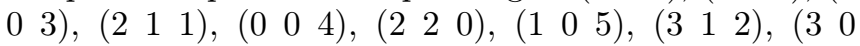
3), (3 21 1), (2 24 ), ( $\left.\begin{array}{lll}4 & 0 & 0\end{array}\right)$, and $\left(\begin{array}{lll}3 & 0 & 5\end{array}\right)$ are in good agreement with the standard values of tetragonal hausmannite $\mathrm{Mn}_{3} \mathrm{O}_{4}$ structure (JCPDS NO. 24-0734) [28]. No additional peaks of other phases have been detected, indicating high purity and moderate crystallinity of the $\mathrm{Mn}_{3} \mathrm{O}_{4}$ product.

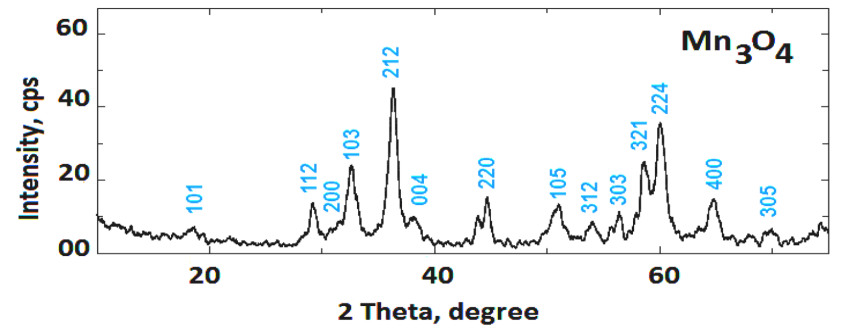

Fig. 2. XRD pattern for the investigated sample.

TABLE I

Some structural properties of the as prepared solid

\begin{tabular}{c|c|c|c|c|c}
\hline \hline Sample & d [nm] & a [nm] & b [nm] & c [nm] & V $\left[\mathrm{nm}^{3}\right]$ \\
\hline $\mathrm{Mn}_{3} \mathrm{O}_{4}$ & 50 & 0.5777 & 0.5777 & 0.9552 & 3.1558
\end{tabular}

$\mathrm{Mn}_{3} \mathrm{O}_{4}$ is well-known to have the normal spinel structure in which the $\mathrm{Mn}^{2+}$ ions occupy the tetrahedral sites while the $\mathrm{Mn}^{3+}$ ions occupy the octahedral sites. $\mathrm{Mn}_{3} \mathrm{O}_{4}$ also has a stable tetrahedral structure in which the oxygen octahedron is tetragonally distorted due to the JahnTeller effect on $\mathrm{Mn}^{3+}$ ions [29]. These results are in good agreement with preparation of hausmannite by using glycine as fuel [24]. The calculated values of the crystallite size $(d)$, lattice constant $(a)$ and unit cell volume $(V)$ of $\mathrm{Mn}_{3} \mathrm{O}_{4}$ phase, depending on the data of X-ray, are given in Table I.

Egg white-assisted combustion route is a simple onestep and "green" strategy for the synthesis of $\mathrm{Mn}_{3} \mathrm{O}_{4}$. This route features environmental benignity, high yield, inexpensive, and high safety. This method brought about 
formation of $\mathrm{Mn}_{3} \mathrm{O}_{4}$ via the heat treatment of a mixture of calculated amounts of both manganese nitrate and egg white at $400{ }^{\circ} \mathrm{C}$ for 15 min on hot-plate without any indication for other crystalline by-products such as $\mathrm{MnO}$ or $\mathrm{Mn}_{2} \mathrm{O}_{3}$. Similar results were observed with presence of glycine instead of egg white [24]. However, the recent work for our research group showed that a mixture of $\mathrm{Mn}_{2} \mathrm{O}_{3}$ and $\mathrm{MnO}_{2}$ can be formed by heating of $\mathrm{Mn}$ nitrate on hotplate at $400{ }^{\circ} \mathrm{C}[24]$.

\subsection{Morphological characteristics}

Scanning electron micrographs (SEM) can be used for study the morphology of the as-synthesized sample as shown in Fig. 3. The exact examination of this figure shows formation of spongy, homogeneous, and fragile material with appearance of voids and pores in the asprepared solid.
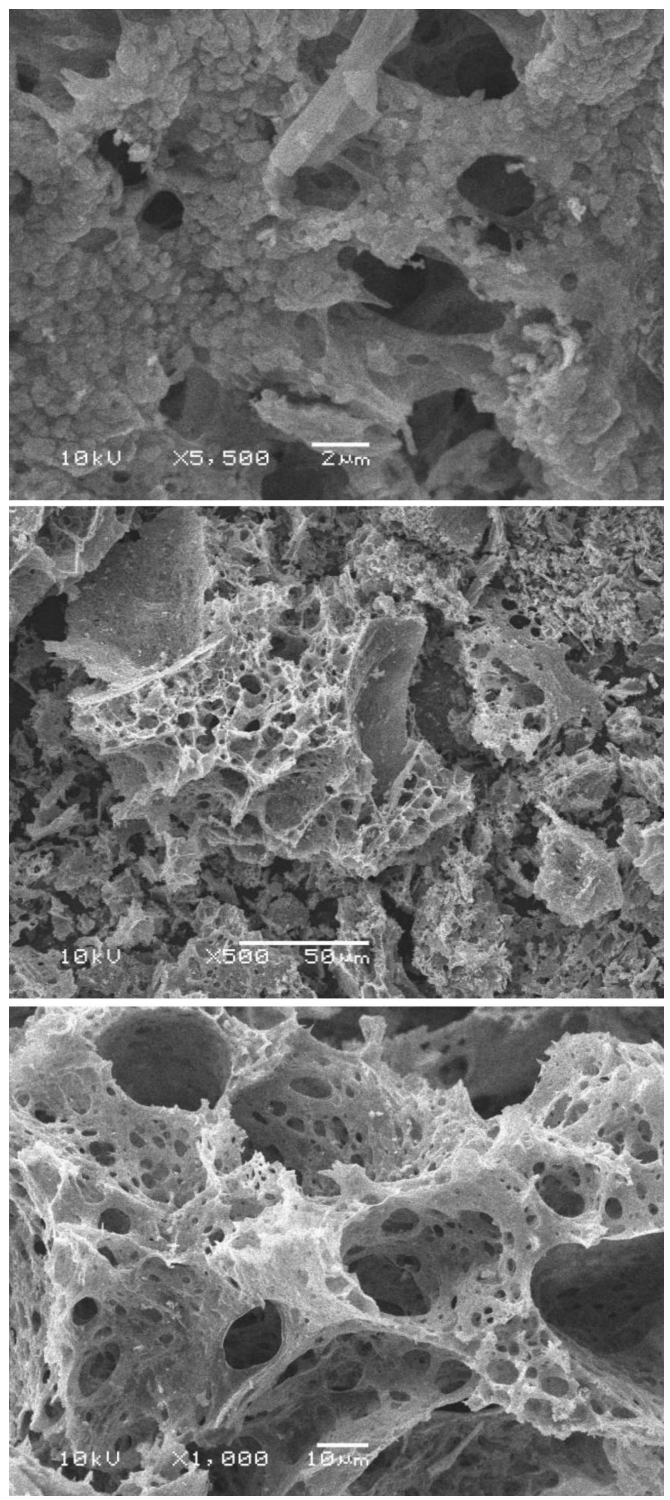

Fig. 3. SEM images for the as-prepared sample.

\subsection{EDX measurements}

Figure 4 shows EDX measurement of the as-prepared sample at $20 \mathrm{keV}$. This measurement displays the effective atomic concentrations of different constituents involved in the sample studied. This figure shows that the as-prepared sample consisted entirely of Mn (77.45\%) and $\mathrm{O}(22.55 \%)$ elements. The data of XRD and the ratios between $\mathrm{Mn}$ and $\mathrm{O}$ elements ensured that the asprepared solid consisted entirely of $\mathrm{Mn}_{3} \mathrm{O}_{4}$ phase. However, EDX technique enables us to study of the homogeneity of elements in the as-prepared samples. The concentrations of different constituents at different points over as-synthesized solid are very close to each other indicating the homogeneity of the as-prepared system.

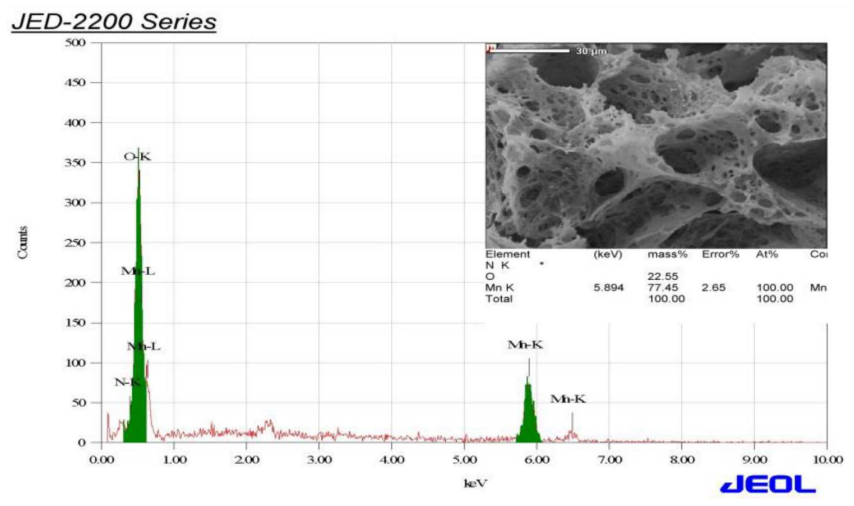

Fig. 4. EDX spectrum for the as-prepared sample.

\subsection{Magnetic studies}

The magnetic properties of nanoparticles are influenced mainly by the method of preparation, cation distribution, grain size, sintering temperature and oxygen parameter and oxygen anion vacancies in lattices $[24,30]$. However, the magnetization of spinel materials originates from the difference in the magnetic moments of the ions at the octahedral lattice sites and those at the tetrahedral lattice sites. The magnetic study was carried out in room temperature on the as-prepared sample with maximum magnetic field at $15 \mathrm{kOe}$. Figure 5 shows the room temperature vibrating sample magnetometer (VSM) plot for the as-prepared sample. $\mathrm{Mn}_{3} \mathrm{O}_{4}$ nanoparticles exhibit paramagnetic behavior. The maximum magnetization $\left(M_{s}\right)$ and coercivity $\left(H_{c}\right)$ observed for as-synthesized sample were $0.887 \mathrm{emu} / \mathrm{g}$ and 36 Oe, respectively, with magnetic retentively $\left(M_{r}\right)$ value of $0.00185 \mathrm{emu} / \mathrm{g}$. The lowest magnetization of the synthesized $\mathrm{Mn}_{3} \mathrm{O}_{4}$ may be due to the spin canting and spin slanting effect of the nanosized particles. This kind of canted moments of spin in the surface of the nanosized particles is caused by the reduction in magnetization. The principle finite size effect arises due to the presence of more number of dangling bonds at the surface which produce a disordered shells enfolded core of spins in an aligned manner [31]. 


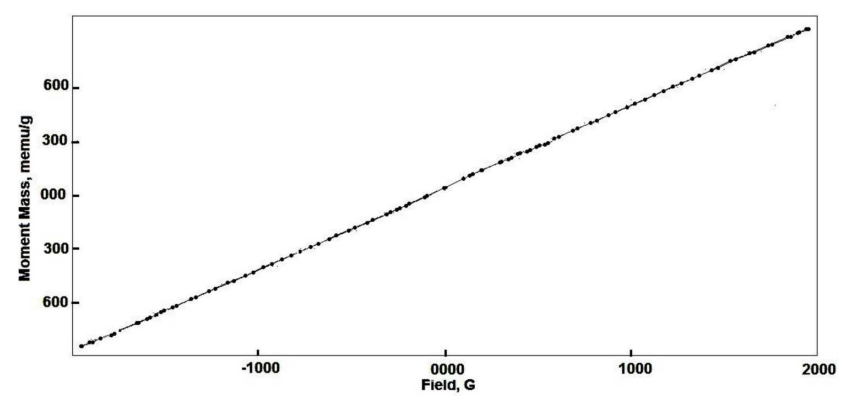

Fig. 5. Magnetic hysteresis loops for $\mathrm{Mn}_{3} \mathrm{O}_{4}$ sample.

\section{Conclusion}

$\mathrm{Mn}_{3} \mathrm{O}_{4}$ nanoparticles were successfully prepared by using combustion method at $400^{\circ} \mathrm{C}$ in the presence of glycine. X-ray structural analyses confirmed that $\mathrm{Mn}_{3} \mathrm{O}_{4}$ nanoparticles crystallize in the tetragonal system. In XRD and SEM results, $\mathrm{Mn}_{3} \mathrm{O}_{4}$ nanoparticles exhibit a crystallite size at $50 \mathrm{~nm}$. EDX spectra proved the presence of $\mathrm{Mn}$ and $\mathrm{O}$ and also confirmed the composition of the sample. SEM micrographs showed spongy, homogeneous, and fragile solid. The magnetization and coercivity of hausmannite were $0.887 \mathrm{emu} / \mathrm{g}$ and $36 \mathrm{Oe}$, respectively. The observed results confirmed that the processing protocol unavoidably influenced the structural, morphological, and magnetic properties of the nanosized hausmannite. Moreover, the processing method may be chosen as an effective tool for attaining successful result in order to tune the behaviour of the nanomaterials with respect to the application.

\section{References}

[1] S. Piligkos, G. Rajaraman, M. Soler, N. Kirchner, J.V. Slageren, R. Bircher, S. Parsons, H.U. Gudel, J. Kortus, W. Wernsdorfer, G. Christou, E.K. Brechin, J. Am. Chem. Soc. 127, 5572 (2005).

[2] N. Yoshikai, S.L. Zhang, K.I. Yamagata, H. Tsuji, E. Nakamura, J. Am. Chem. Soc. 131, 4099 (2009).

[3] A.L.M. Reddy, M.M. Shaijumon, S.R. Gowda, P.M. Ajayan, Nano Lett. 9, 1002 (2009).

[4] M. Mansournia, F. Azizi, N. Rakhshan, J. Phys. Chem. Solids 80, 91 (2015).

[5] H.A. Salam, P. Rajiv, M. Kamaraj, P. Jagadeeswaran, S. Gunalan, R. Sivaraj, I. Res. J. Biol. Sci. 1, 85 (2012).

[6] V.K. Sharma, R.A. Yagard, Y. Lin, Coll. Interface Sci. 145, 83 (2009).
[7] N.R. Jana, Z.L. Wang, T.K. Sau, T. Pal, Curr. Sci. 79, 1367 (2000).

[8] E.J. Grootendorst, Y. Verbeek, V. Ponec, J. Catal. 157, 706 (1995).

[9] E.R. Stobbe, B.A. De Boer, J.W. Geus, Catal. Today 47, 161 (1999).

[10] A.J. Zarur, J.V. Ying, Nature 403, 65 (2000).

[11] S.A. Majetich, Y. Jin, Science 284, 470 (1999).

[12] K. Raj, R. Moskowits, J. Magn. Magn. Mater. 85, 233 (1990).

[13] K.L. Bhowmik, A. Debnath, R.K. Nath, S. Das, K.K. Chattopadhyay, B. Saha, J. Mol. Liq. 219, 1010 (2016)

[14] M. Bhowmik, K. Deb, A. Debnath, B. Saha, Appl. Organomet. Chem. 32, e4186 (2018).

[15] N.H. Singh, K. Kezo, A. Debnath, B. Saha, Appl. Organomet. Chem. 32, e4165 (2018).

[16] K.L. Bhowmik, A. Debnath, R.K. Nath, B. Saha, Water Sci. Technol. 76, 3368 (2017).

[17] N.H. Singh, A. Bera, A. Debnath, B. Saha, Mater. Today Proc. 5, 2300 (2018).

[18] Z. Durmus, A. Baykal, H. Kavas, M. Direkci, M.S. Toprak, Polyhedron 28, 2119 (2009).

[19] F. Davar, M. Salavati-Niasari, N. Mir, K. Saberyan, M. Monemzadeh, E. Ahmadi, Polyhedron 29, 1747 (2010).

[20] R. Mehdizadeh, L.A. Saghatforoush, S. Sanati, Superlatt. Microstruct. 52, 92 (2012).

[21] M. Anilkumar, V. Ravi, Mater. Res. Bull. 40, 605 (2005).

[22] Z. Fang, K. Tang, L. Gao, D. Wang, S. Zeng, Q. Liu, Mater. Res. Bull. 42, 1761 (2007).

[23] N. Wang, L. Guo, L. He, X.O. Ca, C.P. Chen, R. Wang, S.H. Yang, Small 3, 606 (2007).

[24] N.M. Deraz, A.A. Abdeltawab, S.S. Al-Deyab, Asian J. Chem. 26, 2120 (2014).

[25] M.M. Selim, N.M. Deraz, A.A. El-Asmy, O. El-Shafey, J. Alloys Comp. 506, 541 (2010).

[26] N.M. Deraz, A.A. Abdeltawab, M.M. Selim, O. El-Shafey, A.A. El-Asmy, S. Al-Deyab, Salem, J. Industr. Eng. Chem. 20, 2901 (2014).

[27] B.D. Cullity, Elements of X-ray Diffraction, AddisonWesley, 1976, Ch. 14.

[28] L. Liu, H.X. Yang, J.J. Wei, Y.Z. Yang, Mater. Lett. 65, 694 (2011).

[29] D.P. Dubal, R. Holze, RSC Adv. 2, 12096 (2012).

[30] E.M. Mohammed, K.A. Malini, P. Kurian, M.R. Anantharaman, Mater. Res. Bull. 37, 753 (2002).

[31] Y. Tian, D. Li, J. Liu, H. Wang, J. Zhang, Y. Zheng, T. Liu, S. Hou, Electrochim. Acta 257, 155 (2017). 